\title{
MODAL ANALYSIS OF VERTICAL WIND TURBINE BLADE
}

\author{
Lee Zhou Yi, Choe-Yung Teoh*
}

\author{
Faculty of Engineering, \\ Tunku Abdul Rahman University College, \\ *Email: joeyleezy95@gmail.com \\ Phone: +6012-5258373
}

\begin{abstract}
Wind turbines cannot simply be installed in Malaysia due to low wind speed condition. The project has analyzed the existing wind turbine blade (Aeolos-V 1k) design based on modal properties using computational approach (ANSYS Workbench) and redesign it. The modal analysis is simulated to observe natural frequency and corresponding mode shaped of the system under free vibration. The flow induced vibration can cause blade failure due to resonance or fatigue. Fluid Structural Interaction (FSI) ANSYS is used to the determined the interaction between the wind flow and the blade. Harmonic Response ANSYS is used to analyze the frequency response of the blade under wind induced vibration. After modification, the first mode has increased from $91.42 \mathrm{~Hz}$ to 102.12, since it is more than $50.92 \mathrm{~Hz}$ (Turbine maximum operating frequency), resonance would not occur during operating condition. The Aeolos-V's blade has been modified by using teak wood material and redesign the blade for weight reduction and aim for lower blade cost. The weight of modified blade has reduced $72.8 \%$ after using teak wood and the efficiency of the wind turbine also increased. Modified design has been tested under Malaysia maximum wind speed of $9.44 \mathrm{~m} / \mathrm{s}$, the yield stress of teak wood $(10.3 \mathrm{MPa})$ is higher than the maximum stress $(4.2 \mathrm{MPa})$ obtained under force vibration which gives safety factor of 2.4 . Hence, modified blade is reliable, efficient and more economic for Malaysia.
\end{abstract}

Keywords: Vertical Wind Turbine Blade, Flow Induced Vibration, Wind Energy, ANSYS Simulation.

\section{INTRODUCTION}

Renewable energy has lower impact on the environment because they are clean energy. However, there are no statistical data shown that Malaysia has installed any wind farm. The main reason of this issue is due to low average wind speed in Malaysia. Mersing has the maximum wind speed of $9.44 \mathrm{~m} / \mathrm{s}$ in Malaysia [1]. To ensure that wind turbine blade designed can withstand the maximum wind speed in Malaysia. Hence, the operating frequency for designed wind turbine blade is going to be analyzed with 9.44 $\mathrm{m} / \mathrm{s}$ wind load. There are two types of wind turbine which are horizontal axis wind turbine (HAWT) and vertical axis wind turbine(VAWT). VAWT are well design to harness energy in turbulent flow and low wind speed, which is more applicable for Malaysia wind condition. Darrieus rotor with straight blades called $\mathrm{H}$-rotor. $\mathrm{H}$ - rotor has blades with airfoil cross-section as seen from the top view of turbine. H-rotor wind turbine can be design for higher tip speed ratio [2]. Force vibration occur if a system is continuously induced by an external force. Wind induced is the external force that allowed the wind turbine blade rotates to generate electricity from mechanical 
movement. Resonance occurs. when the operating. frequency approaches to the natural. frequency of a system. The result will produce attendant growth of vibration amplitude. Vibration resonance can cause serious damage to the object or it shorten an object's life usage.

\section{METHODOLOGY}

Aeolos - V 1k is a vertical axis wind turbine blade selected from Aeolos Wind Turbine Company for the project testing modal. The mechanical specification of testing modal is listed in Table 1 . The modal is selected because its rated wind speed of $10 \mathrm{~m} / \mathrm{s}$ is the closest wind speed required to Mersing average wind speed, $5.4 \mathrm{~m} / \mathrm{s}$. The selected design is the least bulky structure in the wind turbine market, as higher rated power required higher rated wind speed. Modal analysis is used to identify the vibration characteristic of a system when the system is under operating condition. Five modes shapes and natural frequencies are selected to simulate modal properties of Aeolos-V's blade in ANSYS Modal.

\begin{tabular}{ll} 
Table 1. Specification of Aeolos-V-1k & \\
\hline Aeolos-V 1k & Specification \\
\hline Type of Wind Turbine & Giromill Darrieus \\
Number of blades & 3 pieces \\
Blade material & Aluminium Alloy \\
Blade profile & NACA0018 \\
Rotor radius & $1 \mathrm{~m}$ \\
Span length blade & $2.8 \mathrm{~m}$ \\
Chord length of the blade & $0.37 \mathrm{~m}$ \\
Pitch angle & 8 \\
Height of the wind turbine & $12 \mathrm{~m}$ \\
Rated wind speed & $10 \mathrm{~m} / \mathrm{s}$ \\
Tip speed ratio & 3.36 \\
Testing max. wind speed & $24 \mathrm{~m} / \mathrm{s}$ (Italy) \\
\hline
\end{tabular}

Wind energy is extracted from turbulent flow, the energy conversion can be horizontal axis wind turbine or vertical axis wind turbine. Model used in Fleunt Setup is K-epsilon Realizable with transient time solver. In this project is focusing on VAWT. The wind flow toward wind turbine blade is turbulence and while spinning the blades it creates more turbulence K-epsilon. Realizable model is used for turbulence flow specially on strong pressure flow, rotating and recirculating flow. The left side of the boundary wall is velocity inlet with $24 \mathrm{~m} / \mathrm{s}$ velocity magnitude. The rest of the boundary wall are pressure-outlets, the boundary is initialized and the wind load is calculated. Fluid

Structure Interaction Analysis used to analyze the effect of aerodynamic forces exerted on a solid structure with maximum wind force at $24 \mathrm{~m} / \mathrm{s}$. The wind flow is simulated the with specified wind speed in ANSYS Fluent. Wind load is then imported in Static Structural ANSYS to simulate the stress field wind load interaction with wind turbine blade structure. Harmonic response analysis used to determine the effect of loading in term of steady-state response of a linear structure. Force vibration is obtained from Static Structural ANSYS, the maximum equivalent stress generated in 
Static Structural ANSYS is consider as applied pressure on the wind turbine blade. The natural frequencies also obtain from Modal ANSYS.

The Aeolos-V's wind turbine blade is modified with different materials shown in Table 2. The purpose of modifying Aeolos-V's wind turbine blade is to reduce wind turbine blade weight, since Malaysia wind speed is low. Wind turbine blade does not need to withstand strong wind force and certain material of the blade can be reduced.

Table 2. Mechanical properties of blade materials [3].

\begin{tabular}{llll} 
Material & Aluminium Alloy & Carbon Fibre & Teak Wood \\
\hline Density $\left(\mathrm{kg} / \mathrm{m}^{3}\right)$ & 2770 & 1600 & 581 \\
Young's Modulus (MPa) & 71000 & 70000 & 420 \\
Poisson Ratio & 0.33 & 0.10 & 0.02 \\
Blade Weight $(\mathrm{kg})$ & 127.49 & 73.64 & 34.98 \\
\hline
\end{tabular}

Three suggested hollow designs of wind blade are tested in Modal ANSYS shown in Figure 1. The blade profile still using NACA 0018 to remain the aerodynamic characteristic of Aeolos's wind turbine blade.

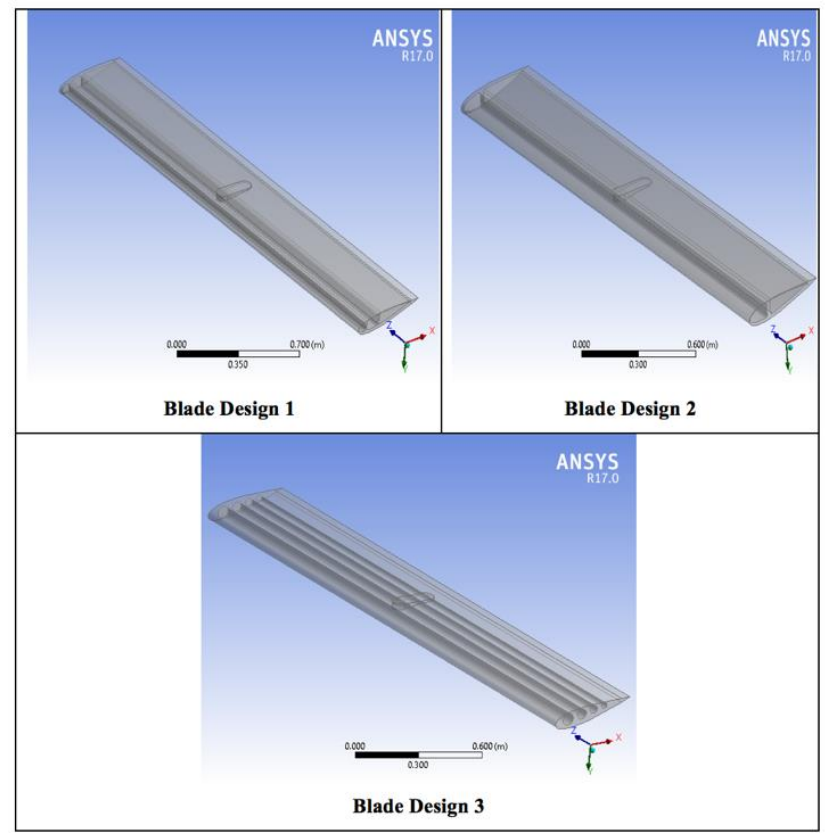

Figure 1. Types of new blade design.

\section{RESULTS AND DISCUSSION}

Modal analysis shows different natural frequency has different mode shapes in Figure 2 with reference of previous researcher [4]. First mode and second mode have flap-wise vibration characteristic. Second mode is the most. critical mode because the bending of each end of the blade are in same direction. Other modes are edge-wise mode and complex mode where they are not as critical as the first two modes. This is because does not consume much energy during wind turbine operation. 


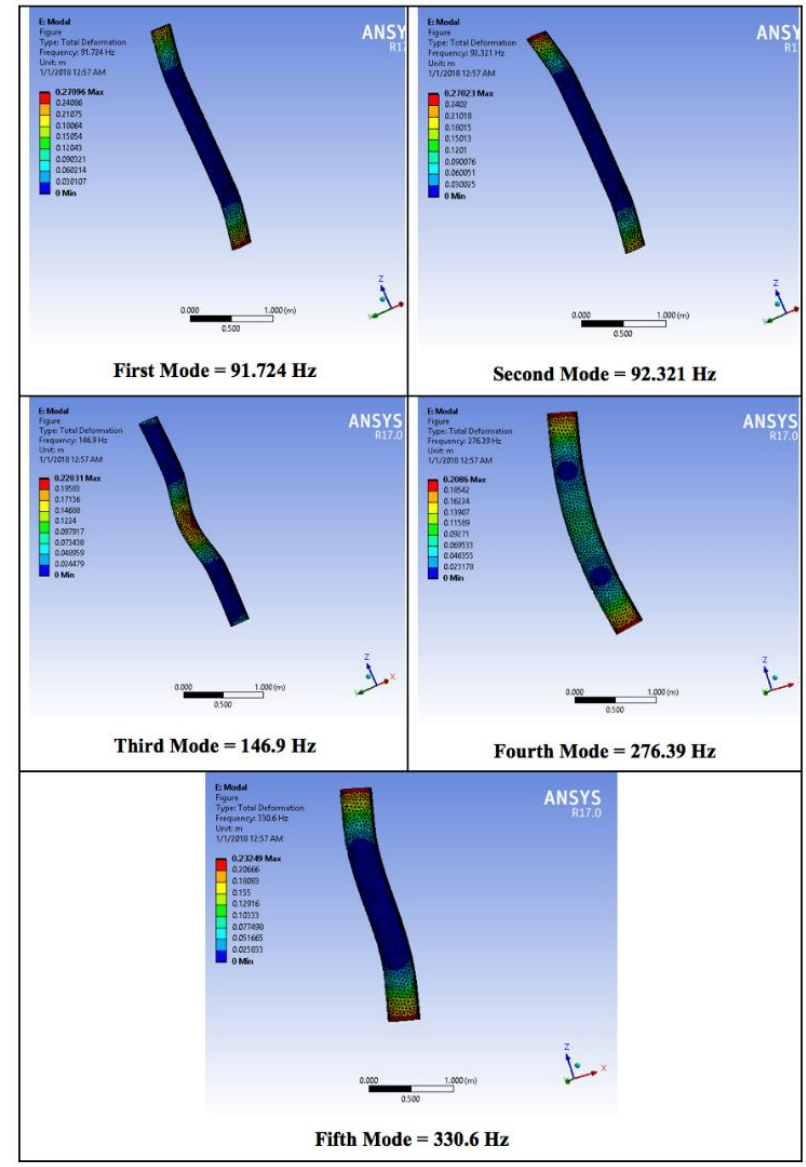

Figure 2. Mode shape for first five natural frequency of Aeolos-V's blade.

When the wind turbine blade is rotating, wind force exerted perpendicularly on the surface of the blade. The bending mode in flap-wise direction absorb more wind force more compared the other modes. The equivalent stress of $2.35 \mathrm{MPa}$ is used as the pressure field on the blade that cause vibration. The result of stress is insert in the harmonic response analysis to determine the operation frequency of the blade. The effect of stress and deformation under force vibration is generated according to each frequency response in Table 3. Table 3 also shows the results of each operating frequency under wind speed of $24 \mathrm{~m} / \mathrm{s}$.

Table 3. Mode shapes, equivalent stress, deformation of the frequency response.

\begin{tabular}{ccccc}
\hline Modes & Mode Shape & Frequency $(\mathrm{Hz})$ & $\begin{array}{c}\text { Equivalent Stress } \\
(\mathrm{MPa})\end{array}$ & $\begin{array}{c}\text { Deformation } \\
(\mathrm{mm})\end{array}$ \\
\hline 1 & Flap-wise & 91.72 & 12.80 & 0.9444 \\
2 & Flap-wise & 92.32 & 15.21 & 1.118 \\
3 & Complex & 146.90 & 16.20 & 0.6931 \\
4 & Edge-wise & 276.39 & 34.70 & 0.3139 \\
5 & Complex & 330.60 & 4.50 & 0.0027 \\
\hline
\end{tabular}

Second mode is the most critical mode as the blade deform inward in Figure 3. The end of the blade tip has the maximum deformation. The maximum stress is at the supports of the blade. Flap-wise vibration is more critical as less amount of stress can create high deformation. The fifth mode has the least mode of $4.5 \mathrm{MPa}$ and it also can the least deformation in Figure 3. Different wind load excited different frequency 
response which can affect the stress of the blade. Under wind load of $24 \mathrm{~m} / \mathrm{s}$ results high stress in fourth mode and least stress in fifth mode.

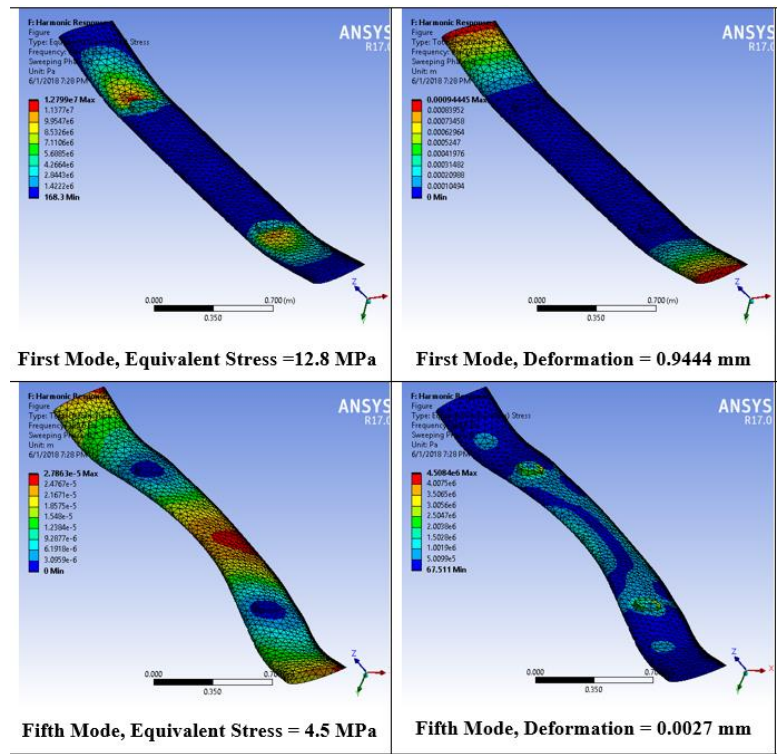

Figure 3. Equivalent stress and deformation of first mode and fifth mode.

In common wind turbine market, most of the company such as Aeolos used aluminum alloy because it can withstand higher wind speed and is less expensive. Malaysia has maximum wind speed of $9.44 \mathrm{~m} / \mathrm{s}$ in Mersing. The modal properties of new types of material such as carbon fibre and teak wood is listed in Table 4. The natural frequency of carbon fibre blade and teak wood blade first mode more than $50.92 \mathrm{~Hz}$. It means that after change to new material, the aerodynamic characteristic can be remained as Aeolos-V's blade. Teak woods are have lighter weight of $34.98 \mathrm{~kg}$ and cost reduction. Hence, teak wood is selected as new material. The first mode of the new blades with one support in table are lower than operating frequency of wind turbine blade $(50.93 \mathrm{~Hz})$ in Table 4 . Hence, it is too risky to remove one support. Design 3 with two supports has significantly higher first mode as compare to blade with one support. Blade Design 3 are more manufacture friendly.

Table 4. modal results for different materials and blade designs.

\begin{tabular}{lllllll}
\hline Modes & $\begin{array}{l}\text { Aluminium } \\
\text { Alloy }\end{array}$ & $\begin{array}{l}\text { Carbon } \\
\text { Fibre }\end{array}$ & $\begin{array}{l}\text { Teak } \\
\text { Wood }\end{array}$ & $\begin{array}{l}\text { Blade } \\
\text { Design 1 } \\
\text { with one } \\
\text { support }\end{array}$ & $\begin{array}{l}\text { Blade } \\
\text { Design 2 } \\
\text { with one } \\
\text { support }\end{array}$ & $\begin{array}{l}\text { Blade } \\
\text { Design 3 } \\
\text { with one } \\
\text { support }\end{array}$ \\
\hline 1 & 91.72 & 116.81 & 102.12 & 26.983 & 28.362 & 31.994 \\
2 & 92.32 & 117.42 & 102.72 & 42.53 & 43.174 & 38.045 \\
3 & 146.90 & 188.34 & 164.1 & 100.77 & 101.57 & 96.475 \\
4 & 276.39 & 375.76 & 317.13 & 150.13 & 145.2 & 164.11 \\
5 & 330.60 & 443.62 & 377.46 & 183.69 & 180.49 & 204.55 \\
\hline
\end{tabular}

After operating frequency response analysis tested under maximum wind speed of $9.44 \mathrm{~m} / \mathrm{s}$, the maximum stress obtains from wind induced vibration is $4.2 \mathrm{MPa}$. the yield stress for teak wood is $10.3 \mathrm{MPa}$. The safety factor of the modified blade is 2.4 . The design is safe to used under Malaysia maximum wind speed. The weight of the 
blade has been reduced as compared to Aeolos-V's blade. The weight reduced $72.8 \%$ from the Aeolos-V' Blade. The main reason is because low density of teak wood. As the weight of the blade reduce, the efficiency of the wind turbine increases. Hence, the modified design of vertical wind turbine can be applied at Mersing, Malaysia

\section{CONCLUSION}

Flow induced vibration is vital concern when design wind turbine blade. Modal properties of Aeolos- $\mathrm{V}$ blades have determined. The natural frequency and the corresponding mode shapes has been determined in Modal ANSYS. The first mode is the most critical mode as it has flap-wise bending mode. Other mode such as edge-wise mode and complex mode are less critical because these modes absorb less wind energy during operating wind turbine blade. The modified blade after undergoing modal analysis and operating frequency analysis, the results have shown that it would not have resonance effect and fatigue problem when applied in Malaysia. The modified blade are environmental friendly, low cost and light weight. It is very suitable to be use under low wind speed condition. Hence, Malaysia has potential to installed wind turbine as new form of renewable energy source with the modified blade. The weight has been reduced $72 \%$ from $127.49 \mathrm{~kg}$ to $34.96 \mathrm{~kg}$. As the weight of the blade reduce, the efficiency of wind turbine increases. The maximum stress obtained from the blade under wind induced vibration is 4.2 MPa. The yield stress of teak wood is $10.3 \mathrm{MPa}$ and factor of safety is 2.4. Hence, the modified blade can be applied in Malaysia without having fatigue failure.

\section{ACKNOWLEDGEMENTS}

I would like to acknowledge Tunku Abdul Rahman University College for providing a good environment and facilities for me to perform my studies and research. I would also like to thank my supervisor Dr. Teoh Choe-Yung who has been giving me support and guide me throughout this project.

\section{REFERENCES}

[1] Islam, M.R., Saidur, R. and Rahim, N.A., 2011. Assessment of wind energy potentiality at Kudat and Labuan, Malaysia using Weibull distribution function. Energy, 36(2), pp.985-992.

[2] Bhutta, M.M.A., Hayat, N., Farooq, A.U., Ali, Z., Jamil, S.R. and Hussain, Z., 2012. Vertical axis wind turbine-A review of various configurations and design techniques. Renewable and Sustainable Energy Reviews, 16(4), pp.1926-1939.

[3] Babu, K.S., Raju, N.S., Reddy, M.S. and Rao, D.N., 2006, June. The material selection for typical wind turbine blades using a MADM approach \& analysis of blades. In Proceedings of 18th International Conference on Multiple Criteria Decision Making (MCDM 2006), Chania, Greece, June (pp. 19-23).

[4] Lemu, H.G., 2015. Advances in numerical computation based mechanical system design and simulation. Advances in Manufacturing, 3(2), pp.130-138. 